\title{
A new species of Taeniacanthus (Copepoda: Taeniacanthidae) parasitic on two pufferfish species, Marilyna meraukensis and M. darwinii (Teleostei: Tetraodontidae), from Australia
}

\author{
Danny Tang ${ }^{1,2}$
}

\author{
${ }^{1}$ Department of Zoology (M092), The University of Western Australia, 35 Stirling Highway, Crawley, Western Australia 6009, \\ Australia; \\ ${ }^{2}$ Laboratory of Aquaculture, Graduate School of Biosphere Science, Hiroshima University, 1-4-4 Kagamiyama, Higashi- \\ Hiroshima, Hiroshima 739-8528, Japan
}

\begin{abstract}
A new species of Taeniacanthidae (Copepoda, Cyclopoida), Taeniacanthus kiemae sp. n., is described based on adult female and male specimens collected from the branchial cavity wall of Marilyna meraukensis (de Beaufort) and M. darwinii (Castelnau) (Teleostei, Tetraodontidae) caught in Australian waters. The new species differs from its congeners by having the following combination of characters in the adult female: 1) maxilla armed with a stout terminal process and two small elements; 2) multiple rows of spinules on the large pectinate process of the antenna; 3) an extremely long and thin maxilliped claw; 4) second exopodal segment of leg 1 with eight setae; 5) third exopodal segment of leg 3 with three spines and four setae; 6) third exopodal segment of leg 4 with three spines and two setae; and 7) each spine on the free exopodal segment of leg 5 with a subterminal flagellum. Taeniacanthus kiemae is the second copepod species reported from M. meraukensis and M. darwinii and the first taeniacanthid species reported from pufferfishes in Australia.
\end{abstract}

Keywords: fish parasite, taxonomy, pufferfish, parasitic copepod

The pufferfish genus Marilyna Hardy (Teleostei, Tetraodontidae) contains three species: M. pleurosticta (Günther), M. darwinii (Castelnau) and M. meraukensis (de Beaufort). Marilyna pleurosticta lives in estuaries along the Australian east coast, whereas M. darwinii and $M$. meraukensis typically inhabit mangrove estuaries and occasionally the lower reaches of freshwater streams in northern Australia and southern New Guinea (Hardy 1982, Allen 1999, Allen et al. 2002). Only one parasite, the mesoparasitic copepod Majalincola buthi Tang et Kalman, 2008 (Ergasilidae von Nordmann, 1832), has been recorded thus far from M. meraukensis and M. darwinii. The fully metamorphic adult females of $M$. buthi were found attached between the bases of two gill filaments with their postantennary and neck regions embedded into the gill arch of M. meraukensis and M. darwinii captured in northern Australia (Tang and Kalman 2008). In this paper, a new parasitic species belonging to the copepod genus Taeniacanthus Sumpf, 1871 (Taeniacanthidae C. B. Wilson, 1911) is described based on material collected from preserved specimens of M. meraukensis and M. darwinii captured in Australian waters.

\section{MATERIALS AND METHODS}

Copepod samples were collected from preserved specimens of $M$. meraukensis and M. darwinii accessioned at the Western Australian Museum (WAM), Perth, Australia, and the Museum and Art Gallery of the Northern Territory (MAGNT), Darwin, Australia. The branchial cavity and gills on the right-side of each museum fish specimen were exposed by initially using a scalpel and/or scissors to make a slit from the dorsal end of the gill slit opening to nearly the posteroventral border of the eye, followed by another incision from the ventral end of the gill slit opening towards the lower lip, and lastly using forceps to lift up the operculum. The inner operculum, branchial cavity wall, gill filaments and gill arches were subsequently examined for copepods using a dissection microscope. Copepods were removed from the hosts with fine forceps and preserved in $70 \%$ ethanol.

Preserved copepod specimens were soaked in lactic acid for a minimum of $24 \mathrm{~h}$ prior to examination using an Olympus SZ60 dissection microscope and Olympus BX50 compound microscope. Selected specimens were measured intact using an ocular micrometer and/or dissected and examined according to the wooden slide procedure of Humes and Gooding (1964). Measurements given are the mean. Illustrations were drawn with the aid of a drawing tube. Morphological terminology follows Dojiri and Cressey (1987) and Huys and Boxshall (1991) and fish names conform to FishBase (Froese and Pauly 2011). Type and/or voucher material are deposited at WAM and MAGNT.

Address for correspondence: D. Tang, Laboratory of Aquaculture, Graduate School of Biosphere Science, Hiroshima University, 1-4-4 Kagamiyama, Higashi-Hiroshima, Hiroshima 739-8528, Japan. Phone: +81-82-424-7989; E-mail: copepods@gmail.com 


\section{RESULTS}

\section{Taeniacanthus kiemae sp. $\mathrm{n}$.}

Figs. 1-30

Female (Figs. 1-27): Body (Fig. 1) $2.68 \mathrm{~mm}$ long (excluding caudal setae) and $1.09 \mathrm{~mm}$ wide $(\mathrm{n}=4)$. Prosome composed of broad cephalothorax (first pedigerous somite fused with cephalosome) and progressively narrower pedigerous somites 2 to 4 . Urosome comprised of 5 th pedigerous somite, genital somite and 4 free abdominal somites. Genital somite wider $(372 \mu \mathrm{m})$ than long $(216 \mu \mathrm{m})$. Abdomen $462 \mu \mathrm{m}$ long and $250 \mu \mathrm{m}$ wide; first 3 abdominal somites naked; ventral surface of anal somite (Fig. 2) with 3 interrupted rows of spinules anteriorly and distolateral row of spinules. Caudal ramus (Fig. 3) longer $(147 \mu \mathrm{m})$ than wide $(62 \mu \mathrm{m})$, bearing 6 setae (seta I not observed); setae IV and V each with outer row of barbules and inner row of spinules, all others naked; row of minute spinules present at base of setae II and III; seta VII shortest, about half length of seta III.

Rostral area (Fig. 4) with vertical sclerotized plate and 2 groups of pores on ventromedian surface. Antennule (Fig. 5) 6-segmented (articulation between ancestral segments XIV-XVII and XVIII-XX not expressed); armature formula: $5,15,8,4,2+1$ aesthetasc, and $7+1$ aesthetasc; second segment shortest of 6 . Antenna (Figs. $6,7)$ 4-segmented; coxobasis longer than length of endopodal segments combined, bearing distal seta; first endopodal segment with stout inner seta; second endopodal segment bearing 2 unequal pectinate processes and clawlike spine (large pectinate process with several rows of spinules and long seta; small pectinate process with row of minute spinules and small blunt seta); third endopodal segment with 2 claw-like spines and 4 unequal naked setae. Postantennal process (Fig. 8) stout, with curved tine.

Labrum (Fig. 9) with row of blunt spinules along posterior margin. Mandible (Fig. 10) armed with broad hyaline seta plus terminal and subterminal blades; both blades spinulate along inner margin. Paragnath (Fig. 11) with proximal patch of setules. Maxillule (Fig. 12) lobate, bearing 2 bristled setae, 3 naked setae and anterior knoblike process. Maxilla (Fig. 13) 2-segmented; syncoxa with cluster of pores; basis with stout terminal process bearing spinules at distal end and 2 highly reduced spines. Maxilliped (Figs. 14, 15) 3-segmented; syncoxa irregularlyshaped, bearing naked seta; basis with 2 proximal naked setae; terminal (endopod) segment an extremely thin and elongate claw, bearing basal protrusion with naked seta and row of teeth along distal margins.

Legs 1-4 biramous (Figs. 16-24); leg 1 with 2-segmented rami; remaining legs with 3-segmented rami. Armature on rami of legs $1-4$ as follows (Roman numerals $=$ spines; Arabic numerals $=$ setae; int. $=$ intermediate spine):

\begin{tabular}{|c|c|c|c|c|}
\hline & Coxa & Basis & Exopod & Endopod \\
\hline Leg 1 & $0-1$ & $1-1$ & $1-0 ; 8$ & $0-1 ; 7$ \\
\hline Leg 2 & $0-0$ & $1-0$ & I-0; I-1; II, I, 4 & $0-1 ; 0-1 ;$ II, I, 3 \\
\hline Leg 3 & $0-0$ & $1-0$ & I-0; I-1; II, I, 4 & $0-1 ; 0-1 ;$ II, I, 2 \\
\hline Leg 4 & $0-0$ & $1-0$ & I-0; I-1; II, I, 2 & $0-1 ; 0-1 ; \mathrm{I}, \mathrm{I}$, int. \\
\hline
\end{tabular}

Leg 1 (Fig. 16) flattened and expanded. Posterior margin of intercoxal sclerite with 2 patches of fine spinules on each side of medial cleft. Coxa with large anteromedial process, hyaline membrane on outer border and patches and rows of spinules; basis with small patch of spinules on ventral surface plus row of spinules and small hyaline membrane on posterior border. Posterior margin of intercoxal sclerite of legs 2-4 (Figs. 17, 20, 22) arched, bearing 2 patches of fine spinules. Leg 2 coxa (Fig. 17) with distolateral row of spinules; basis (Fig. 17) with posterior row of spinules and inner patch of fine spinules. Leg 2 exopodal segments (Fig. 18) with outer row of spinules; first 4 exopodal spines highly sclerotized, each with accessory subterminal flagellum and spinules along margins; apical spine with spinules along outer border and short row of pinnules distomedially; third exopodal segment with well-developed distolateral protrusion armed with minute spinule. Leg 2 endopodal segments (Fig. 19) ornamented as in leg 2 exopod; second segment with small lateral protrusion; third segment with protrusion on each side of outer proximal spine; spines spinulate along margins. Coxa and basis of legs 3 and 4 identical to those of leg 2. Leg 3 rami identical to those of leg 2 , except leg 3 endopod (Fig. 21) with 1 fewer seta on third segment. Leg 4 exopod (Fig. 23) similar to that of leg 2, except with 2 minute spinules on distolateral protrusion and 2 fewer setae on third segment. Leg 4 endopod (Fig. 24) similar to that of leg 2, except armed with 2 spines and intermediate spine.

Leg 5 (Figs. 25, 26) uniramous, 2-segmented. Protopodal segment armed with dorsolateral naked seta and several rows of spinules along posterior margin. Free exopodal segment with patches and rows of spinules on inner surface; bearing 3 well-developed, spinulate spines (each spine bearing subterminal flagellum) and naked seta; each element with row of spinules at base. Leg 6 (Fig. 27) vestigial, represented by opercular plate armed with 3 short naked setae at egg sac attachment area.

Male (Figs. 28-30): Body (Fig. 28) $1.65 \mathrm{~mm}$ long (excluding caudal setae) and $0.66 \mathrm{~mm}$ wide $(\mathrm{n}=5)$. Genital double-somite wider $(237 \mu \mathrm{m})$ than long $(162 \mu \mathrm{m})$. Abdomen $290 \mu \mathrm{m}$ long and $172 \mu \mathrm{m}$ wide, composed of 3 free somites. Caudal ramus longer $(115 \mu \mathrm{m})$ than wide $(50 \mu \mathrm{m})$, bearing similar elements as in female.

Maxilliped (Figs. 29, 30) 4-segmented; syncoxa irregularly-shaped, bearing naked seta; basis robust, armed with 2 proximomedial setae, rows of rounded denticles on posteromedial surface and row of spinules on antero- 
Tang: New species of Taeniacanthus

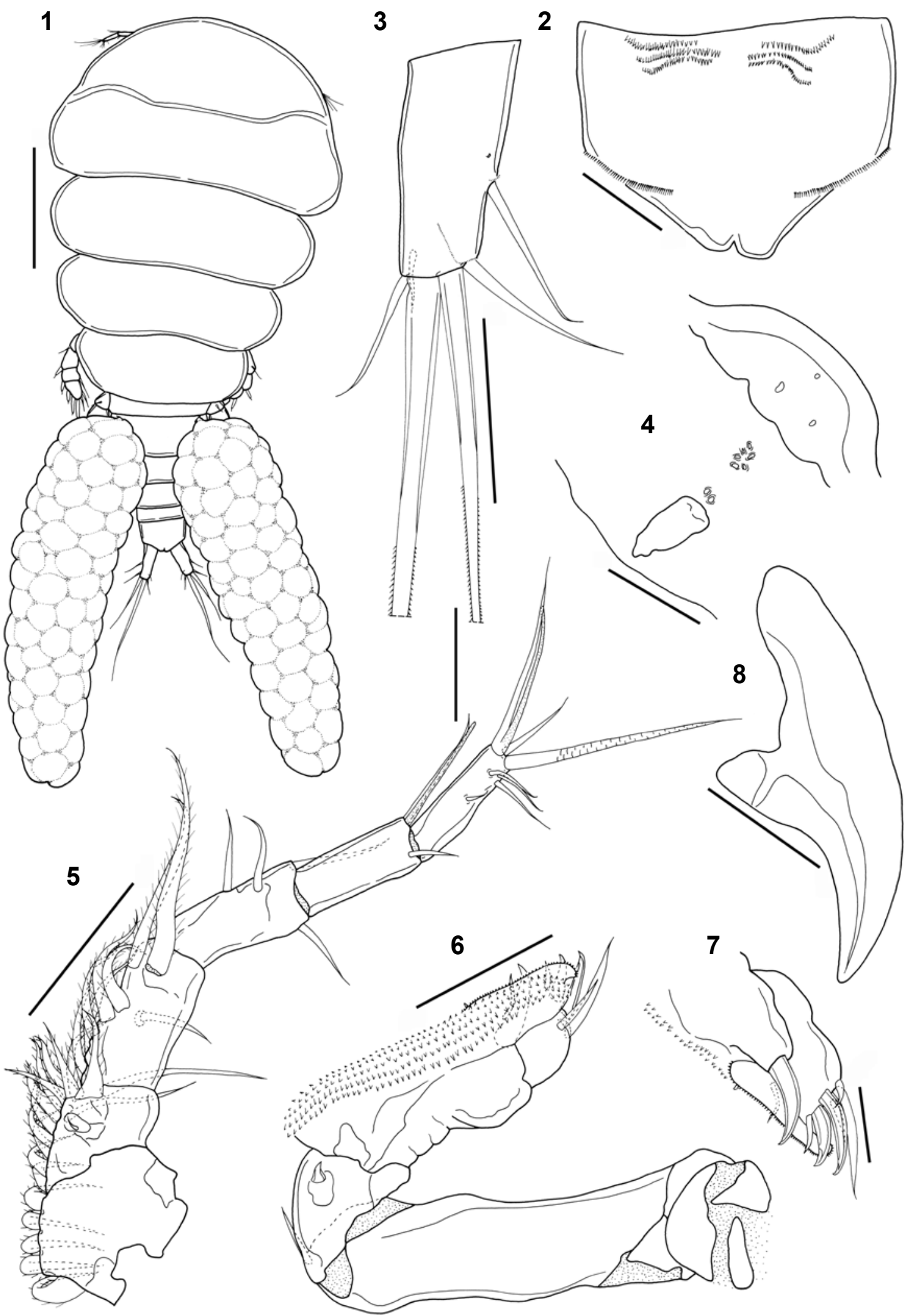

Figs. 1-8. Taeniacanthus kiemae sp. n., female. Fig. 1. Habitus, dorsal. Fig. 2. Anal somite, ventral. Fig. 3. Caudal ramus, ventral. Fig. 4. Rostral area, ventral. Fig. 5. Antennule, ventral. Fig. 6. Antenna, medial. Fig. 7. Distal end of antenna, lateral. Fig. 8. Postantennal process, medial. Scale bars: Fig. $1=0.50 \mathrm{~mm}$; Figs. 2, 4, 6, $8=50 \mu \mathrm{m}$; Figs. $3,5=0.10 \mathrm{~mm}$; Fig. $7=25 \mu \mathrm{m}$. 


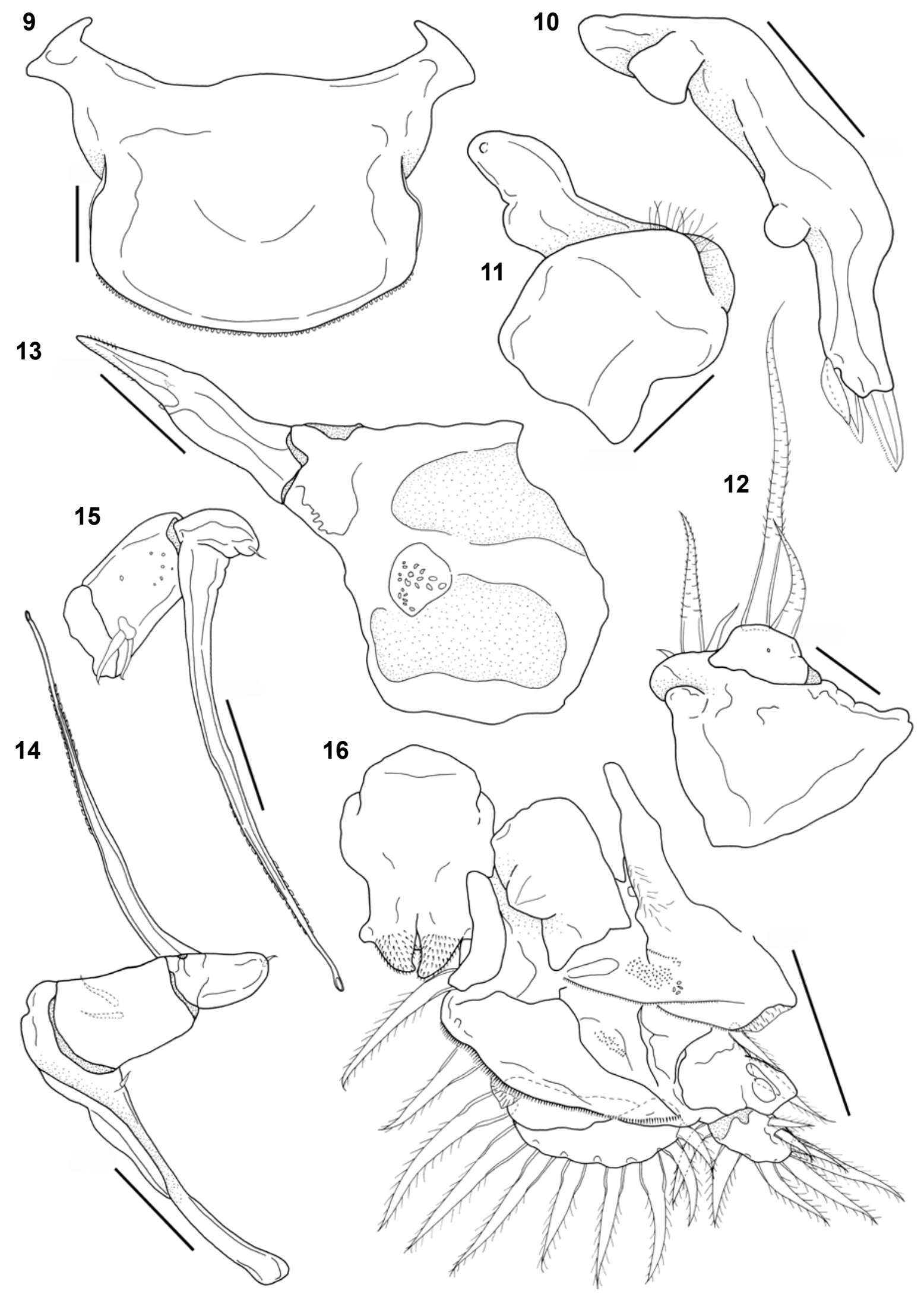

Figs. 9-16. Taeniacanthus kiemae sp. n., female. Fig. 9. Labrum, ventral. Fig. 10. Mandible, dorsal. Fig. 11. Paragnath, ventrolateral. Fig. 12. Maxillule, dorsal. Fig. 13. Maxilla, ventral. Fig. 14. Maxilliped, posterolateral. Fig. 15. Same (syncoxa omitted), anterior. Fig. 16. Leg 1, anterior. Scale bars: Figs. $9,11,12=25 \mu \mathrm{m}$; Figs. $10,13-15=50 \mu \mathrm{m}$; Fig. $16=0.10 \mathrm{~mm}$. 


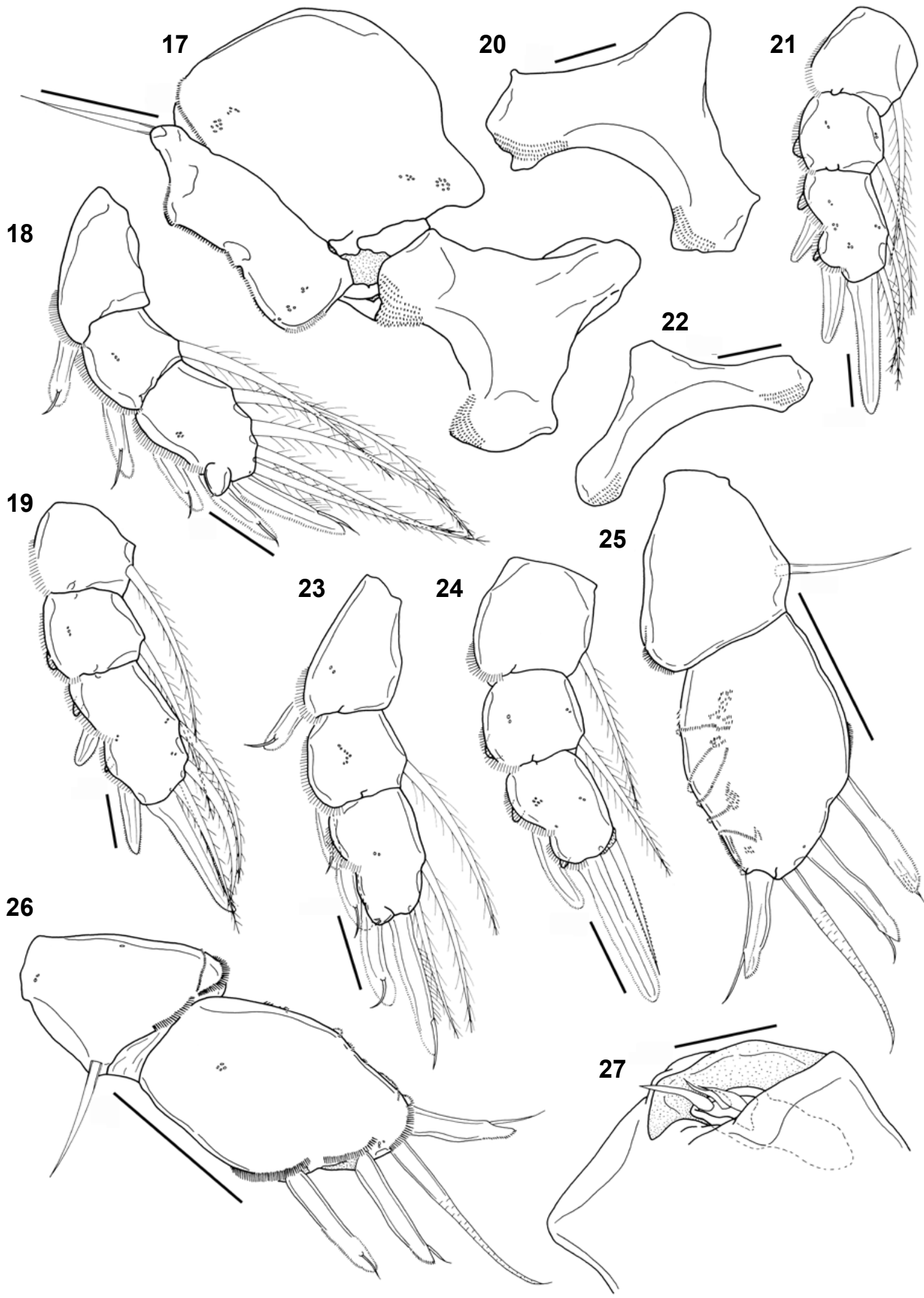

Figs. 17-27. Taeniacanthus kiemae sp. n., female. Fig. 17. Leg 2 intercoxal sclerite, coxa and basis, anterior. Fig. 18. Leg 2 exopod, anterior. Fig. 19. Leg 2 endopod, anterior. Fig. 20. Leg 3 intercoxal sclerite, anterior. Fig. 21. Leg 3 endopod, anterior. Fig. 22. Leg 4 intercoxal sclerite, anterior. Fig. 23. Leg 4 exopod, anterior. Fig. 24. Leg 4 endopod, anterior. Fig. 25. Leg 5, ventromedial. Fig. 26. Same, dorsolateral. Fig. 27. Leg 6, dorsal. Scale bars: Figs. 17, 25, $26=0.10 \mathrm{~mm}$; Figs. $18-24,27=50 \mu \mathrm{m}$. 


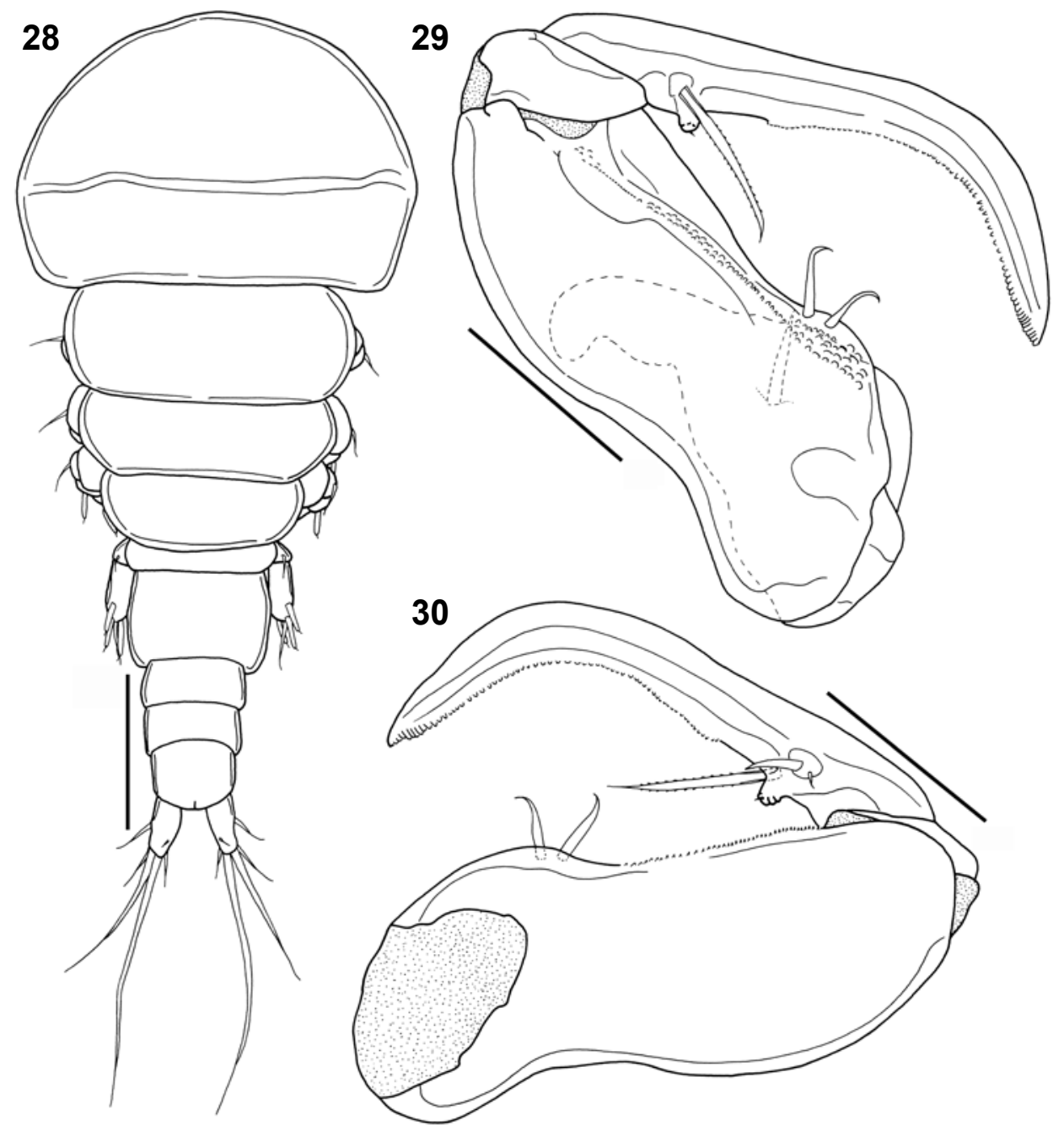

Figs. 28-30. Taeniacanthus kiemae sp. n., male. Fig. 28. Habitus, dorsal. Fig. 29. Maxilliped, posterior. Fig. 30. Same (syncoxa omitted), anterior. Scale bars: Fig. $28=0.25 \mathrm{~mm}$; Figs. $29,30=50 \mu \mathrm{m}$.

medial surface; first endopodal segment small, unarmed; second endopodal segment a strongly curved claw, with row of denticles along concave margin, 1 long bristled seta, 2 small unequal setae and proximal crenulated process bearing minute setule. Leg 6 (not figured) vestigial, represented by unarmed opercular plate on posteroventral surface of genital double-somite.

Type host: Marilyna meraukensis (de Beaufort) (Teleostei, Tetraodontidae).

Other host: Marilyna darwinii (Castelnau).

Site of infection: Branchial cavity wall.

Type locality: Field Island, Northern Territory, Australia.

Other localities: Kalumburu Mission, Western Australia, Australia; Wildman River, Northern Territory, Australia; West Alligator Head, Northern Territory, Australia; East Arm, Darwin Harbour, Northern Territory, Australia; Broome, Western Australia, Australia.

Material examined: Holotype female (MAGNT Cr014995), allotype male (MAGNT Cr014996) and 2 para- types (1 male and 1 damaged female) (MAGNT Cr014992Cr014993), ex 2 M. meraukensis (MAGNT S.14500-004), Field Island, Northern Territory, Australia, 4 June 1997. Additional specimens include: 1 female and 2 males (WAM C38589, C38752-C38753), ex 1 M. meraukensis (WAM P.13485.001), Kalumburu Mission, Western Australia, Australia, October 1963; 2 females, 1 male and 1 copepodid (MAGNT Cr014982-Cr014984), ex 1 M. meraukensis (MAGNT S.14663-005), Field Island, Northern Territory, Australia, 4 June 1998; 1 female (MAGNT Cr014985), ex M. meraukensis (MAGNT S.14440-001), Wildman River, Northern Territory, Australia, 28 May 1997; 1 female and 1 male (MAGNT Cr014986), ex 1 M. meraukensis (MAGNT S.14662-003), West Alligator Head, Northern Territory, Australia, 3 June 1998; 1 female and 1 male (MAGNT Cr014988), ex 1 M. meraukensis (MAGNT S.10718-010), East Arm, Darwin Harbour, Northern Territory, Australia, 31 December 1982; 1 female, 2 males and 6 copepodids (MAGNT Cr014989-Cr014991), ex 2 M. meraukensis (MAGNT S.14449-004), West Alligator Head, Northern Territory, Australia, 30 May 1997; and 1 female (WAM C38560), 
ex M. darwinii (WAM P.32225.001), Broome, Western Australia, Australia, 1982.

Ety mology: On behalf of my five siblings, this species is named after our beloved mother Kiem.

Remarks. The new species shares a maxilla armed with a stout terminal process and two small elements with four congeners: T. yamagutii (Shiino, 1957), T. fugu Yamaguti et Yamasu, 1959, T. kitamakura Yamaguti et Yamasu, 1959, and T. pectinatus Yamaguti et Yamasu, 1959. These four congeners are also parasites of pufferfishes. Taeniacanthus kiemae differs from them, except $T$. pectinatus, by having eight setae (rather than nine) on the second exopodal segment of leg 1 and three spines and four setae (rather than three and five) on the third exopodal segment of leg 3. Taeniacanthus pectinatus was described by Yamaguti and Yamasu (1959) based on a single non-ovigerous female specimen found on Sphoeroides sp. collected in the Seto Inland Sea, Japan. This species has not been reported since its original discovery. Dojiri and Cressey (1987) questioned the validity of $T$. pectinatus as they regarded its armature formula of II, I, 2 on the third exopodal segment of leg 4 as unusual. As T. kiemae shares the same armature of II, I, 2 on the third exopodal segment of leg 4 with $T$. pectinatus, the latter species is considered herein as a valid taxon. A detailed description of $T$. pectinatus based on ovigerous females is still needed, however, to confirm its taxonomic standing. Taeniacanthus kiemae can be easily distinguished from $T$. pectinatus by having multiple rows of spinules on the large pectinate process of the antenna, an exceptionally long and thin maxilliped claw, a patch of fine spinules on the inner margin of the basis of legs 3 and 4 and a subterminal flagellum on each spine of the free exopodal segment of leg 5. The discovery of $T$. kiemae not only represents the second copepod species reported from M. meraukensis and $M$. darwinii but also the first record of a taeniacanthid species parasitic on pufferfishes from Australia.

Acknowledgements. Many thanks to Helen Larson (Museum and Art Gallery of the Northern Territory) and Barry Hutchins (Western Australian Museum) for allowing me to collect copepods from preserved fish specimens in their care. This study was made possible through financial support from the Department of Zoology at the University of Western Australia and the Japan Society for Promotion of Science Postdoctoral Fellowship (grant No. 21-09117).

\section{REFERENCES}

Allen G. 1999: Marine Fishes of Tropical Australia and Southeast Asia. The Western Australian Museum, Perth, 292 pp.

Allen G.R., Midgley S.H., Allen M. 2002: Freshwater Fishes of Australia. The Western Australian Museum, Perth, 394 pp.

Dojiri M., Cressey R.F. 1987: Revision of the Taeniacanthidae (Copepoda: Poecilostomatoida) parasitic on fishes and sea urchins. Smithson. Contrib. Zool. 447: 1-250.

Froese R., Pauly D. (Eds.) 2011: FishBase. World Wide Web electronic publication. www.fishbase.org [8 May 2011].

Hardy G.S. 1982: Two new generic names for some Australian pufferfishes (Tetraodontiformes: Tetraodontidae), with species' redescriptions and osteological comparisons. Aust. Zool. 21: $1-26$.
Humes A.G., Gooding R.U. 1964: A method for studying the external anatomy of copepods. Crustaceana 6: 238-240.

Huys R., Boxshall G.A. 1991: Copepod Evolution. The Ray Society, London, $468 \mathrm{pp}$.

Tang D., Kalman J.E. 2008: A new genus and species of mesoparasitic ergasilid (Copepoda: Cyclopoida) from brackish water pufferfishes collected in northern Australian waters. Syst. Parasitol. 69: 89-99.

Yamaguti S., Yamasu T. 1959: Parasitic copepods from fishes of Japan with descriptions of 26 new species and remarks on two known species. Biol. J. Okayama Univ. 5: 89-165. 